\title{
Incidence of Trocar (Port) Site Hernias After Laparoscopic Cholecystectomy-Study of 100 Cases
}

\author{
Sheikh Firoj Kabir ${ }^{1}$, Md. Anowarul Haque ${ }^{2}$
}

\begin{abstract}
:
Context: Laparoscopic surgery are increasing day by day in our country. Incisional hernia can occur in any abdominal surgery and laparoscopic surgery is not immune to this complications. The aim of this study is to ascertain the incidence of Trocar(port) site hernia after the laparoscopic cholecystectomy.

Study design: Retrospective study

Place and period of study: June 2009 to June 2011 in Dhaka City.

Materials and Methods: 100 cases of laparoscopic cholecystectomy were studied. The study was conducted to determine the complications of laparoscopic cholecystectomy.

Results: Port site hernia is less common in younger age group (40-55 yrs) i.e. $0.65 \%$ and more in older age group (55-70 years) i.e. 2.8\%. Coexisting diseases like diabetes mellitus, bronchial asthma and infected cases are more prone to these complications.
\end{abstract}

Conclusion: As the new operative procedure are emerging in our country, care must be taken to overcome the incidence of complications.

Key Words: Trocar (Port) site hernia, Laparoscopic cholecystectomy, Complication.

Introduction:

There is now a little doubt that laparoscopic procedures, particularly laparoscopic cholecystectomy, have revolutionized intra-abdominal surgery and became the gold standard for the treatment of symptomatic cholelithiasis ${ }^{1}$. This fact was in part due to the use of small incisions, which produce less wound pain and result in speedy post operative recovery. Port site hernia is one of the complications of laparoscopic cholecystectomy which is mentioned in both local and international literature ${ }^{8}$. Herniation through port site wounds is the result of inadequate closure of the musculo aponeurotic layers of the abdominal wall ${ }^{2}$. The over all percentage is size related with the majority of hernias occurring in wounds larger than $10 \mathrm{~mm}$ and $12 \mathrm{~mm}$ ports. Port site hernias are more common in

1. Asso. Prof. of Surgery. Tairunnesa Memorial Medical College, Gazipur, Dhaka.

2. Consultant, Surgery, Comilla Medical College Hospital. Address of Correpondence: Dr. Sheikh Firoj Kabir the umbilical ports. Portsite hernias may present acutely with intestinal obstruction, often due to partial entrapment of knuckle of bowel (Richter type of hernias) $)^{2}$. The diagnosis may not be immediately apparent, so often there is no superficial skin bulge. CT scan has been recommended for establishing diagnosis. This study is performed to see the prevalence of incisional hernia after laparoscopic cholecystectomies.

\section{Materials and Methods:}

This retrospective study was conducted on 100 patients underwent laparoscopic cholecystectomy in different hospitals in Dhaka city from June 2009 to June 2011. Our study included 28 male and 72 female patients who underwent laparoscopic cholecystectomy for symptomatic gall stones. Their age ranged from 23 to 75 years with mean age of 42 years. All patients were assessed clinically and underwent routine investigations including liver function tests. The diagnosis was mainly confirmed by ultrasonography. Eighty patients presented with pain in right hypochondrium and twenty gave a 
Bangladesh J. Anat. 2011; 9(2) : 110-112

history of dyspepsia. Thirty seven patients had associated diabetes mellitus, hypertension and morbid obesity. A second generation cephalosporin was given one hour before laparoscopic procedure. Standard 4 ports technique, umbilical port of $10 \mathrm{~mm}$ and epigastric port of $10 \mathrm{~mm}, 2$ ports of $5 \mathrm{~mm}$ at right hypochondriac region and right iliac fossa were used. Linea alba and skin both in epigastrium and umbilicus were stitched with non absorbable polypropylene suture material. Clinical assessments were performed in all cases. Patients undergone laparoscopic surgery were admitted with a history of pain around the umbilicus and also swelling around the umbilical port . Cough impulse was positive. Patients were not aware of any hernia at the site either before or after laparoscopic surgery.

Complete blood cell count, X-ray chest and ultrasound of the abdomen was done. Contrast Enhanced Computerised Tomography(CECT) scan was done in some patients.

A defect in the midline at the level of umbilicus with herniation of intra abdominal contents through the defect were found. With the diagnosis of port site hernia, patients were taken for surgery.

Some of the patients were treated by open laparotomy and some were treated laparoscopically but all were treated with prolene mesh repair under general anaesthesia. Closure were performed using poly propylene suture.

Most of the patients remained well in the post operative period and was discharged on the 5th post operative day in a satisfactory condition.

\section{Result:}

In this study port site hernia was found in the older age group (40 to $60 \mathrm{yrs}$ ). Only 1 case (i.e. 1.67\%) had hernia in this group.

On the other hand in the $60-75$ age group out of 30 patients 1 patient (i.e. 3.33\%) had port site hernia.

Only the umbilical port was found vulnerable for herniation, as it is $10 \mathrm{~mm}$ port. All the patient developed port site hernia after about 1-1.5 years of operation. No one have any major complications like intestinal obstruction, or any acute illness due to hernia.
Table-I

Distribution of age:

\begin{tabular}{lcc}
\hline Age Limit in years & $\begin{array}{c}\text { Number of } \\
\text { Patients }(\mathrm{n})\end{array}$ & $\begin{array}{c}\text { Percentage } \\
(\%)\end{array}$ \\
\hline $20-40$ & 10 & 10 \\
$40-60$ & 60 & 60 \\
$60-75$ & 30 & 30 \\
\hline \multicolumn{4}{c}{ Table-II } \\
& Diagnosis \\
\hline Diagnosis & Number of & Percentage \\
& Patients (n) & $(\%)$ \\
\hline Acute on chronic & 40 & 40 \\
cholecystitis & 60 & 60 \\
Chronic cholecystitis & 60 \\
\hline
\end{tabular}

Table-III

Incidence of Hernia:

\begin{tabular}{lcc}
\hline Age in years & $\begin{array}{c}\text { Number of } \\
\text { patients }(\mathrm{n})\end{array}$ & $\begin{array}{c}\text { Incidence of } \\
\text { Hernia }(\%)\end{array}$ \\
\hline $20-40$ & 10 & $0 \quad(0)$ \\
$40-60$ & 60 & $1(1.67)$ \\
$60-75$ & 30 & $1(3.33)$ \\
\hline
\end{tabular}

\section{Discussion:}

Hernias at port sites following laparoscopic surgery were reported, with the use of larger ports than $10 \mathrm{~mm}$ or when I0mm wound port was extended for removal of distended gall bladder. It may be expected that this problem will increase as larger cannulas are used $^{1}$. In our study 02 cases of port site hernias were observed after follow up for 02 years. On the other hand as in international and in local literature incisional hernias at port sites following laparoscopic surgery is mentioned ${ }^{8}$. The significant incidence of umbilical defects in patients undergoing laparoscopic surgery calls for accurate diagnosis and good techniques ${ }^{3}$. The incidence of incisional hernia might be reduced by avoiding un-necessary wound extension and the use of non absorbable sutures for closure of defects larger than $10 \mathrm{~mm}$. It had also been suggested that when the pneumoperitoneum is expelled before the extraction of the port, the 
pressure gradient between the intraperitoneal gas and the atmosphere allows omentum or small bowel to become attached to the end of the cannula, the subsequent withdrawal of which results in the hernia ${ }^{6}$. Simple digital examination of the port site after removal of the trocar may help to prevent this complication but this may be unreliable when using $10 \mathrm{~mm}$ port sites and in obese patients, require meticulous closure of musculoaponeurotic layer with monofilament polypropylene ${ }^{1}$.

Various factors have been implicated in the pathogenesis of trocar site hernias. Large trocar size, incomplete closure of fascia at the trocar site, midline trocars, stretching the port site for organ retrieval, the effect of a partial vacuum while port withdrawal, obesity, poor nutrition and operation site infection are some of the common factors related to the development of trocar site hernias. Richter's hernia occurs when a part of the bowel wall herniates through the port site. Computed tomography and gastrointestinal contrast studies have been used to aid the diagnosis of trocar site hernias. The management of most of these hernias include an explorative laparotomy, widening of the trocar site, reduction of the hernia and further surgeries based on the bowel viability. The rarity of small bowel obstruction encountered due to the development of an early onset type of Richter's hernia in a lateral port and the successful laparoscopic assisted technique employed to resolve the problem have been highlighted.

\section{Conclusion:}

Port site wound hernia is a rare complication of laparoscopic cholecystectomies and ports wounds are rather small to stitch.

\section{References:}

1. Borovyide M., Semenium lus Potikoov-et al. Parietal incarcinated hernia of paraumblical trocar access. Klin. Khir. (Ukraine). Jan., 2004; (1): p. 52.

2. CuschericA, Houston G. Cuscherie and Gream Houston. Essential of surgical practice. $4^{\text {th }} \mathrm{ed}$. Abdominal minimal access sur-gery. 2000; 1 : p. 508.

3. Wicks A., Vovyvodic, Scroop R. Incisional hernia and small bowel obstruction following laparoscopic surgery. Computed tomography diagnosis. Australas Radiol. (Australia) Aug., 2000; 44 (3): 331-2.

4. Cadeddu M. O., Schlacta C. M., Mamazzaj et al. Soft tissue images. Trocar site hernia after laparoscopic procedure. Can J Surgery, Feb., 2002; 45 (1): 9-10.

5. Sanz-Lopes, Martovez RR, Nuxer-Pena JPC, et al. Incisional hernia after laparoscopic vs open cholecystectomy. Surs Endosc. (Germany) Sep., 1999; 13 (9): 922-4.

6. Cole AS, Vinpond MN, Espiner HJ. Br J Surg. 1995; 82:1134-5.

7. Duncan C, Gerghty JG, Keye S, Rasheed A, Lynch $G$. Large bowel herniation after laparoscopic cholecystectomy. J. R. Coll. Surg. Edinbr, 1995; 40: 119.

8. Gondal Sh., Khan ZA, Gondal KM. Complications of Laparoscopic cholecystectomy ; Pak J Surg. 1996; 12(1): 15-16. 